\title{
Competitive tendering in an entry regulated market—an accident waiting to happen?
}

\author{
Jørgen Aarhaug ${ }^{1}$
}

Received: 18 June 2014 / Accepted: 9 April 2015 /Published online: 23 April 2015

(C) The Author(s) 2015. This article is published with open access at SpringerLink.com

\begin{abstract}
Introduction Competitive tendering was introduced in the contract segment of the Norwegian taxi industry in 2005; a market characterised by entry regulation. Using this reform as a natural experiment this research looks into how competitive tendering has resulted in different outcomes in different segments of the taxi market and which explanations are best at describing the results.

Methods The main sources of data are the taximeter data and case studies, conducted as part of a study of the rural taxi industry in Norway. This data have been supplemented by interviews with key stakeholders and data on prices and volumes from various purchasers of transport services, such as health corporations and county governments.

Results The empirical data shows a lot of variation. There are very different outcomes in the different cases studied. However, the research shows that competitive tendering has mostly worked according to intention in the most central regions. These are characterised by many potential suppliers and that the tendered contracts are relative small compared with the total size of the market. I rural areas the results differ, with poor results from tendering in the intermediate areas and mostly satisfactory results in the most rural areas.

Conclusions Experience from the Norwegian taxi industry shows that competitive tendering is possible within entryregulated markets. Still, there are issues that remain to be solved, in particular in rural areas. This is due to both interdependency between the purchaser and the service provider, and
\end{abstract}

Jørgen Aarhaug

jaa@toi.no

1 Institute of Transport Economics, Gaustadalleen 21, 0349 Oslo, Norway the size of the markets. For other sectors, the main lessons are that competitive tendering can work, even with regulated entry, but that it needs to be adapted to suit the characteristics of each market. This research shows that there is significant variation within a sector. A tool such as competitive tendering can be well suited in one area, but inappropriate in another. This research suggests that the outcome is related to both hard factors such as market size and number of entrants, but also to factors like interdependency and negotiation climate.

Keywords Taxi regulation - Competitive tendering · Entry regulation $\cdot$ Rural taxi

\section{Introduction}

The provision of public services in rural communities is challenging in many different contexts because population densities are low and distances are often long. The transport component of the cost of providing such services is therefore even more important in rural than in urban or suburban settings. In this paper, I examine the relationship between competition and entry regulation in small taxi markets, and, more generally, the challenges posed by competitive tendering.

In the case of public health care, the realization that transport had become a significant part of costs was one of the arguments when responsibility for the transport of patients was moved from regional authorities, county governments, to newly created health corporations as part of major organizational reform in Norway in 2004. The main objective of the reform was more efficient use of available health funding by creating larger units with state rather than county funding, and by making one and the same authority responsible for both treatment and transport. Health corporations were therefore given the incentive to incorporate transport when costing their decisions on treatment. 
Transportation to and from treatment usually means getting patients from home to hospital, between different hospitals or from hospitals to home, i.e. few passengers per trip and wide area coverage. Within the Norwegian legal framework, this transport can be undertaken in one of three ways: First, by taxi, i.e. a vehicle with a legal taximeter, fewer than 17 seats and registered as a taxi; second, by a private bus company, i.e. whose vehicles have nine or more passenger seats registered under an occasional passenger transport licence; and, third, by the health corporation's own vehicles, i.e. buses on licence but operated by health corporation staff. In the case of all three alternatives, the responsible dispatching unit is located within the health corporation. Transfer of the dispatching service from private taxi companies to the health corporation is common to all alternatives.

Under the previous regulatory framework, transport was conducted by the taxi industry on behalf of county governments. For the industry itself, the transportation of patients was seen as a vital part of demand in rural areas in particular.

Within the Norwegian framework, the taxi industry is subject to entry regulation based on the number of taxi vehicles needed in an area. When a large part of the demand suddenly becomes uncertain - as with the introduction of competitive tendering and competition from other sectors - which has been the case with regulatory reform of the health corporations, an already difficult situation becomes even more difficult. This was the starting point of Osland et al.'s research in 2010 [1] conducted for the Ministry of Transport and Communications with the purpose of mapping areas where the transport service had changed due to the reform, the author was responsible for the empirical part of that report.

In this paper, I start with a description of the taxi industry in Norway and an explanation of the regulatory changes and their different contexts. I go on to discuss the theoretical expectations (Section 2) and empirical findings (Section 3) and, finally, discuss (Section 4) and pinpoint the lessons learned from this natural experiment (Section 5).

\subsection{The Norwegian taxi industry}

In Norway, just as in many other countries, the taxi industry is a form of public transport providing door-to-door service in direct response to demand. Compared to other forms of public transport, vehicles and typical passenger flows are smaller. In Norway, a taxi is defined as a vehicle, with driver, that is available for public hire and does not operate on a fixed schedule. There are few national requirements for vehicles, but one is a maximum number of 17 seats, including the driver. This differs from typical Anglo-Saxon definitions, which differentiate between pre-booked and street-hire vehicles. In terms of value, the Norwegian taxi industry had a turnover of approximately $€ 1.1$ billion in $2013 .{ }^{1}$ Overall, approximately half of

\footnotetext{
${ }^{1}$ http://www.ssb.no/transport-og-reiseliv/statistikker/drosje
}

this was contract work, the major contracting partners being the different health corporations. The total public procurement of taxi services was thus approximately $50 \%$ higher than that of passenger rail transport in Norway ( $€ 0.35$ billion in 2013). ${ }^{2}$ So, even though individual contracts are small, the total value is substantial.

For analytical purposes the taxi business can be divided into several market segments with different characteristics.

The main difference in the taxi market is between single trip and contract work. In single-trip segments, passengers contact the taxi directly (kerb/rank/street) or through a dispatcher (pre-booked). In contract segments, a company or a public body negotiates with a taxi dispatcher over a contract for multiple transport assignments. The contract will typically include a simple payment scheme and discounts on the taximeter rates or on fares calculated after criteria other than the taximeter fare.

The market segments illustrated in Fig. 1 have different characteristics depending on, for example, demand structure, supply structure and price formation. Consequently, the ideal regulation will vary across these segments [3].

The taxi licensing system in Norway is based on the owner-operator as the main unit, and in areas viable economically, owner-operators can be affiliated to a dispatching company. Affiliation is compulsory in urban areas. An operating licence is required, with each owner a qualified driver and each vehicle a separate licence. In principal, one licence per owner, but a licence for a backup vehicle is common. If there are no new applicants for a licence, someone who is already a licenceholder can be assigned more licences. The total number of licences is determined in a variety of ways by different local authorities and county governments are responsible for regulation. The law $^{3}$ requires local government to restrict the number of licences through needs assessment, but does not state how this is to be done. How and the extent to which this form of entry regulation is a barrier to entry will vary. In some areas, there are many applicants for the available licences, while in others the local authorities have great difficulty finding people willing to take on the responsibilities faced by the licence-holder, one of which is a 24-h availability requirement [4].

Furthermore, Norwegian taxi regulations stipulate two-tier pricing. Although the norm is maximum fares set by the Norwegian competition authorities, there are seven exempted areas in which all prices are set by the market. These are

\footnotetext{
${ }^{2}$ http://www.regjeringen.no/nb/dep/sd/dok/regpubl/prop/ 2012-2013/prop-1-s-20122013/3.html?id=703170

${ }^{3} \mathrm{http}: / / w w w . l o v d a t a . n o / a l l / t l-20020621-045-002 . h t m l \# 9$, http://www.lovdata.no/for/sf/sd/td-20030326-0401-003.html last visited July 2013
} 


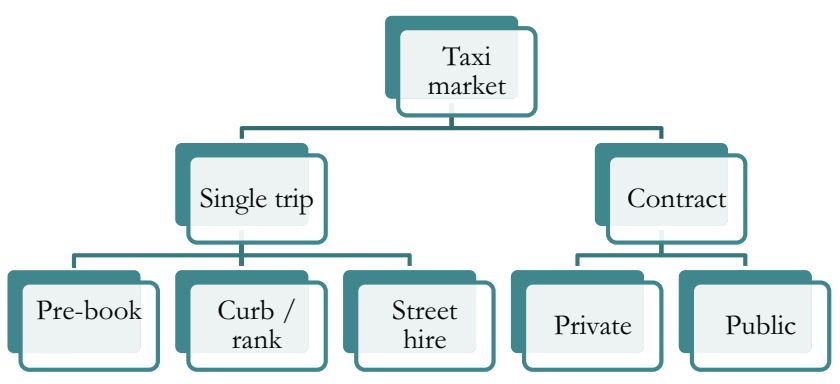

Fig. 1 Taxi market segments (adopted from Longva et al. 2010 [2])

defined by municipal borders and constitute the largest cities in Norway. ${ }^{4}$ The prices in the contract segments are always set in the market, and never regulated by the central authorities.

\subsection{Methods}

The paper is based on research presented in several reports [1-6] on taxi regulation, competitive tendering and conflicting regulatory systems. All of these studies take into consideration a combination of qualitative and quantitative data and are supported here by new interviews of key actors and new analysis of publically available statistics, economic data and production data from various taxi dispatching companies and health corporations, together with licence data from regional governments in Norway. Some of the data collected from earlier reports have been re-analysed. I draw on all these sources of information, but omit data from the reports that are not relevant for the purpose of the paper, including the Norwegian experience of competitive tendering in entryregulated and small markets.

One important source is the data collection and analysis conducted in the Osland et al. (2010) [1] study, which includes a survey of all 19 counties in Norway and an in-depth study of three. In Section 3, examples from comparable municipalities where competitive tendering has had different impacts are selected from parts of the Osland et al. study [1].

\section{Regulation and competition}

From auction theory we would expect prices to reflect the competition situation, i.e. prices dropping in response to the number of entrants increasing. On contract market segments the entrants are the dispatchers or the minibus companies. If the dispatching company is dependent on a contract for its existence, one would expect to find the competitive outcome even in a situation with only one competitor to the incumbent. However, this will only work in the first round of competitive tendering. In the second, the expectation is that there will be

\footnotetext{
${ }^{4} \mathrm{http} / /$ www.lovdata.no/cgi-wift/wiftldles?doc=/app/gratis/ www/docroot/ltavd1/filer/sf-20040225-0485.html\&emne= maksimalprisforskrift*\& last visited July 2013
}

only one actor. If there were no competitors, one would expect the price to be the result of the relative power of the negotiating parties. Because in the short and medium run they are interdependent, it is difficult to predict the outcome.

Looking at the structure of taxi markets there are several reasons why a system based on competitive tendering of public contracts can fail. There is the legal issue concerning entry regulation and of not allowing licences to accompany the contracts. And there are the economic issues of scale and scope giving licence-holders economic benefits from being associated with the largest dispatcher.

The introduction of competitive tendering to an entryregulated industry such as the Norwegian taxi industry raises many theoretical and practical questions. In this section, I present some of the theoretical arguments and follow up with three explanations which I use in the empirical discussion.

\subsection{Arguments for introducing competitive tendering in the Norwegian taxi industry}

The theoretical basis behind the introduction of competitive tendering is that it will result in lower prices for the purchaser through efficiency gains. It is expected that the price in the market will be equal to the second most efficient producer's marginal cost [7]. This is straightforward economic theory, which has been introduced in a number of previously publically run industries, mostly with lower unit costs as a result [8]; it is also part of most European government policies.

The theoretical argument for entry regulation through needs testing is based on increasing returns to scale, i.e. taxi dispatchers with allocated vehicles constitute a network with increasing returns to density. Arnott (1996), among others, has created a model for this argument [9]. Controlling the number of vehicles can also be used as an instrument by which "living wages" are assured in an industry where wages vary with demand. In economic terms, controlling supply is used to increase the attractiveness of the industry for operators and improve the benefits from economies of scale and scope. On a policy level, entry restrictions are seen in the context of nondirect economic support for keeping prices (fares) below market levels and maintaining a 24-h service, even when not economically viable. In effect, a monopoly rent is accepted as compensation for prices below market level and a 24-h service, as these and the network effects dictate an undersupply of taxis, and overcharging in the free market solution.

\subsection{Arguments opposing competitive tendering}

There are at least three arguments suggesting that the conditions for a functioning auction are not in place in the Norwegian taxi industry they relate to the economics created by the present structure of the taxi industry. First, there are 
entry regulations, second, there are economies of scale and, third, there are economies of scope.

1) The entry regulation limits the number of new entrants to the market. It is illegal for the licensing authority to issue a new permit allowing a new entrant on a particular contract. However, it is legal to allocate new licences to particular dispatchers if increased competition in the market is the result. This creates a situation in which there is a limit to the number of potential contractors, unlike the bus service industry, where one tender can attract competitors from other parts of the country or internationally. The number and allocation of the licences between dispatchers must be taken as a given in each tender.

2) There are few or no economies of scale in operating a taxi vehicle, but significant economies of scale in dispatching (see 2.1). As most tendered transport is dependent on a dispatcher functioning as an intermediary between client and driver, there are scale benefits. How large will depend on the form of contract and on the distribution of responsibility between the authority ordering the transport and the dispatcher. This relation has changed during the process of competitive tendering in the direction of more responsibility with the public authority reducing the economies of scale [1]. However, as there are still significant economies of scale in the pre-booked market segment, which is economically important for taxi owners, each owner will prefer to be associated with the largest dispatcher in the area, as this will provide the expected return. A new dispatcher entering the market is therefore faced not only with the normal start-up cost, but also with the licence owners' disincentive to choose the new entrant.

3) Economies of scope come from the fact that taxi demand fluctuates constantly [6]. Taxis operate in different market segments at different times, and consequently the operator will be active in different market segments as a means of utilizing his vehicle efficiently with lower unit costs and higher profits for the owner. Again, this will favour incumbent dispatchers, as they can offer more pre-booked trips from their enlarged network. The incumbent will typically have more licences associated and as a result be able to divide the fixed cost of operating a dispatching company over a larger number of vehicles, and therefore a lower fixed cost per vehicle.

\subsection{Experience from other sectors}

Benefits from the introduction of competitive tendering in public transport have been well documented by, among others, Bekken et al. [8] using Norwegian data and Alexandersson and Pyddoke [10] using Swedish data. The main benefit has been in the form of lower prices. These authors typically find cost reductions of about $20 \%$. Together with the benefits, there has been a restructuring of the bus service industry into fewer and larger companies competing nationally and internationally, rather than just locally $[11,12]$. Over time, competition has been working, with prices remaining low even in the second and later rounds of tendering [10]. Comparable studies of the effect of competitive tendering on the taxi service industry have not been carried out in Norway, and to the author's knowledge nowhere else either.

One of the main developments in the bus service industry following the introduction of competitive tendering has been the establishment of national companies and the introduction of international companies competing with each other for contracts in different regions, when previously competitive tendering companies were mostly local. This has created a repetitive game in which the regulator's main task is in ensuring that no cartels or rigged auctions take place. The move from a non-competitive local industry to a national competitive industry is possibly a development for the taxi industry.

However, in the taxi industry the markets are still mostly local, particularly in non-contract segments. There are dispatching companies operating on a national and international level, but licences are tied to the counties and owner operators, thus creating different game dynamics between the taxi industry and the bus service industry.

Differences can be found when translating these observations into game-theory. In particular, we can expect a particular form of Bertrand competition [13]. If we decide to look at auctions as a non-repetitive game, which it can be argued is the case in rural areas in particular, the competition will need only two competitors in reaching an efficient outcome. As both competitors are faced with the choice of submitting a winning bid, or bankruptcy, following Bertrand's theory they will be expected to submit a competitive bid. However, if so, there will only be one actor at the end of the contract period, and after the contract there will be only one actor left, who will then be expected to submit its future bids as a monopoly supplier. In other words, the local structure of the taxi industry can create local monopolies because of competitive tendering. In this way, competitive tendering can result in reduced competition over time.

\subsection{Expectations}

The rationale for introducing competitive tendering is an expectation from theory; namely, that auctioning provision of the service will allow the most efficient producer to operate [7] and gain experience from other sectors [8]. It will create competition in an otherwise uncompetitive market and promote a more efficient use of public funds. Instead of competition for individual trips (competition in the market), there is competition for a contract in the form of an auction. 
The pre-reform regime prompted a series of questions on the efficiency and transparency of the system [14], mainly questions connected with information asymmetry. County governments perceived themselves as being in a classical principal-agent dilemma unable to distinguish between high and low quality high price actors.

In theory, it is debatable whether or not the taxi industry is a natural monopoly; however, it is common to assume economies of scale in dispatching for the relevant market sizes [11, $15,16]$. Moreover, the expected market structure with local monopolies is observed in rural areas in Norway. In this article, I will assume that the natural monopoly approach is correct.

Owing to the specific regulations of the taxi industry entry regulation, regulated prices (on non-contract market segments) and the obligation to provide transport services at odd hours - actors such as the Taxi Owners' Association have argued that the benefits from competitive tendering, in terms of public savings, are less than the cost in terms of lower service provision. As a result, several other explanations have been put forward, which I discuss below.

\subsubsection{Introducing competitive tendering results in lower prices and better service}

In auction theory [7] it is reasoned that in the auctioning process the auctioneer will be able to confiscate most of the social surplus created by the service.

It is assumed that winning the auction is retaining a value equal to the difference in efficiency between the winner and the second best entrant with a profit similar to the difference in efficiency [7]. The value of the expected outcome is the same in all four forms of conventional auction, but the variation is different. In the contracts in question, a first price, sealed envelope system is used.

Certain conditions have to be met, particularly the need for several entrants, which will vary with the design of the auction. From experience in the Norwegian bus service industry, however, between three and five competitors is sufficient for a competitive outcome [11]. In relation to the taxi industry this means that we can expect a competitive outcome in all major urban areas, and in some rural areas where there is an active minibus service. However, in most rural areas there is often only one non-taxi minibus company and in some there are only taxis providing transport services.

\subsubsection{Lower price and reduced service - quality shading}

Quality shading in the form of lower price and reduced service is a hypothesis that has been presented in several mid-sized cities. This refers to the argument that, with the introduction of competitive tendering, the market is opened up to new smaller dispatching companies, although they must have several "secure" assignments, such as transport for some public authority, if they are to maintain their operations. They are unlikely to compete well on the pre-booked market, because of network economics, and on street market segments, where the network economics are less important, and are small in all but the largest cities in Norway. To secure these contracts, smaller dispatchers submit low bids, but they are unable to secure a steady supply of taxis as licence-holders generally prefer to be attached to the incumbent. The licence-holder's arguments are based on real or perceived efficiency gains from being attached to the incumbent, usually through having better access to the pre-booked market segments.

In economic terms, this is a scenario where low quality takes over from high quality, as the public authority is unable to distinguish between high and low quality before the contract period. Theoretically, this argument is related to Akerlof's [17] market for lemons.

\subsubsection{Unsustainable industry}

The hypothesis that the industry is unsustainable has been fronted predominantly by the Norwegian Taxi Owners' Association with examples from rural areas and abroad (usually Sweden). The argument is that the taxi industry is faced with higher costs than the competing minibus industry, putting it at a disadvantage in the competition for tendered contracts. When disadvantaged, it will lose the auctions. As the contract markets make up a large proportion of the income in rural areas in particular, loss of this kind will result in a situation where there is no longer any economic foundation for a taxi service.

The economics of this argument are that competition takes place on unequal terms. Taxis face stricter licensing requirements; in particular the taximeter, the need for a dispatcher and the 24-h service at regulated prices. The result is that taxis have higher fixed costs than the minibus industry. In areas where contract work is a large share of the total, this is not offset by access to other market segments, and taxis will have to price higher and lose tenders. Again, this will result in bankruptcies and a loss of 24-h service in relevant areas.

In addition, if it is accepted that tendered contracts are of vital importance for the taxi industry, or for rural transport service provision in general, a Bertrand [18] style competition scenario can be constructed, where the loser in the auction exits the market.

\section{Empirical findings}

The main conclusion from the Osland et al. study [1] was that in Norway there had been little change in the availability of taxis in rural areas in the period between the introduction of competitive tendering and the study being carried out. The 
study concludes, however, that there were few cases where there was actual competition on rural taxi contracts. Most tenders received only one bid and this was usually the local taxi service industry. However, there were cases where competition was very real, particularly in cities with more than one dispatching company and in some rural municipalities where there was a well-established minibus industry.

The revenue breakdown for different groups of municipalities (based on centrality) is illustrated in Fig. 2a, b on the basis of information about taxis operating in Hedmark County in eastern Norway, and including all taxis licensed within the county. It can be seen in the Figure that public contracts constitute the bulk of taxi revenue in the least central areas $(69 \%$ on average in the sample). More surprising is that public contracts account for more than half of the revenue in the central municipalities in the sample.

\subsection{Effects of competitive tendering}

In cases where the taxi service industry has been successfully challenged by a minibus company, the effects have been a drastic reduction in the taxi industry. The example of two neighbouring municipalities of similar size and centrality (illustrated in Fig. 4a, b) reflects the difference. ${ }^{5}$

The economic development of the taxi service industry in the municipality of Sør-Odal in Hedmark, Norway-development typical of the industry in Norway-is illustrated in Fig. 3a along with the same development over the same time horizon, but for the neighbouring municipality of Eidskog, in Fig. 3b. Here, the taxi service industry lost the tender for the transport of patients in 2004 and of school children in 2006. As a result, the number of available taxis in Eidskog dropped from seven to two. In Sør-Odal the number of vehicles remained constant over the period [1]. Reflected in the Figures is that transport of the disabled dropped with reduction in the number of available taxis in Eidskog, even though not directly in relation to the tenders.

Figures 2 and 3 show that contract work is important for the taxi service industry and that the service available in other market segments is to a certain degree dependent on number of vehicles, which in turn is dependent on the amount of contract driving.

Looking at data from the neighbouring county of Oppland, two clear observations can be drawn: First, the indexed price development of the different market segments (Fig. 4), and, second, the development in kilometres driven per passenger (Fig. 5).

\footnotetext{
${ }^{5}$ The term "centrality" is used based on the Norwegian payroll tax definition. Norway is divided into seven areas with different pay-roll tax rates, and highest in central areas. http:// www.lovdata.no/for/sf/sv/td-20121127-1213-001.html (last visited July 2013).
}

The development in unit prices for taxis in different market segments from a sample of about $90 \%$ of those in Oppland County is shown in Fig. 4. The line indicates the introduction of competitive tendering. The most interesting observation is that after the introduction of competitive tendering on the health contracts the unit prices in this segment changed less than in the other segments. In all periods the unit price is lower, but after the introduction of competitive tendering the unit price increase seemed to stop completely in this segment but not in the others. In absolute numbers the average unit price in 2007 varied from 13 kroner per kilometre for health transport to 22 kroner per kilometre for transport paid by credit card.

The distance driven by taxis divided by the number of passengers transported in the different market segments is shown in Fig. 5. Throughout the period, the longest trips have been health contract driving, but distance has halved. As the infrastructure has remained more or less constant in the period, the most likely explanation is that there were more passengers per vehicle in the health transport category at the end of the period than at the start. And the most significant dropoff in kilometres per passenger occurred before competitive tendering was introduced.

\section{Discussion}

The relative importance of the contract market segments differs between areas with different degrees of centrality (see Fig. 2a, b). One would therefore expect that the negative effects of competitive tendering would be felt most by the taxi service industry in the outermost rural areas. However, as rural communities typically have only one established transport operator, namely the local taxi dispatcher, the scope for competition is limited.

Looking at the argument in 2.4.1 above, one might expect the introduction of competitive tendering to have resulted in lower prices and better service, and empirical experience suggests (Fig. 4) that at least the lower price component has some support. From interviews conducted in [5, 4], a clear indication is that quality, on average, has improved - informants working in the health corporations and local administration saw this as a result of competition being introduced in the form of competitive tendering. Still, most of the interviewed purchasers can point to single contracts where quality has decreased or there have been issues in relation to quality. The same is the case for the taxi companies, mostly pointing the finger at minibus companies.

Vehicles have improved over the period, as have the auditing abilities of the purchasers. There are examples, such as those documented in [3], where a small dispatcher has had difficulty delivering services at the level stipulated in the contract, but according to [1] this seems to be the exception rather 
Fig. 2 a, b Revenue breakdown for the taxi industry in different groups of municipalities [1]

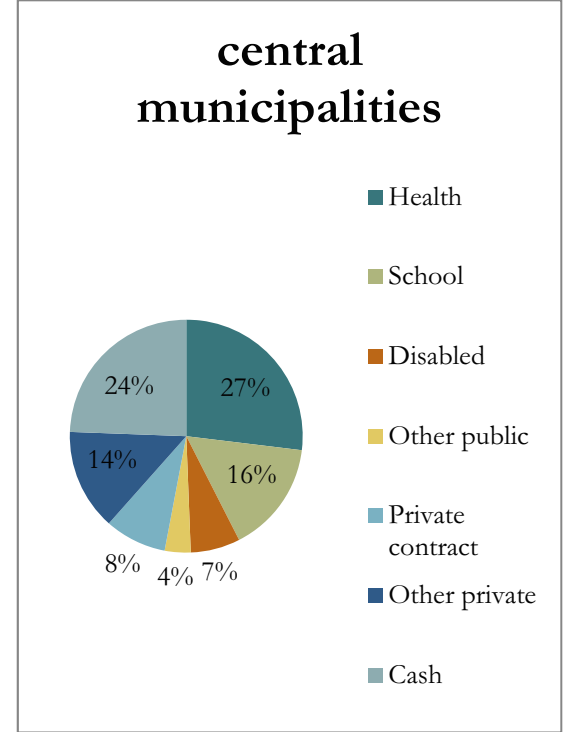

than the rule. There are a number of cases where the quality of the taxi service has been questioned, but only a few can be related to the introduction of competitive tendering.

The argument in Section 2.4.3, 'Unsustainable industry', has some validity in the in-between areas, but not it seems in outermost rural areas. Osland et al. [1] found that only four municipalities out of 430 had lost their taxi service in the period analysed and no direct support for the connection
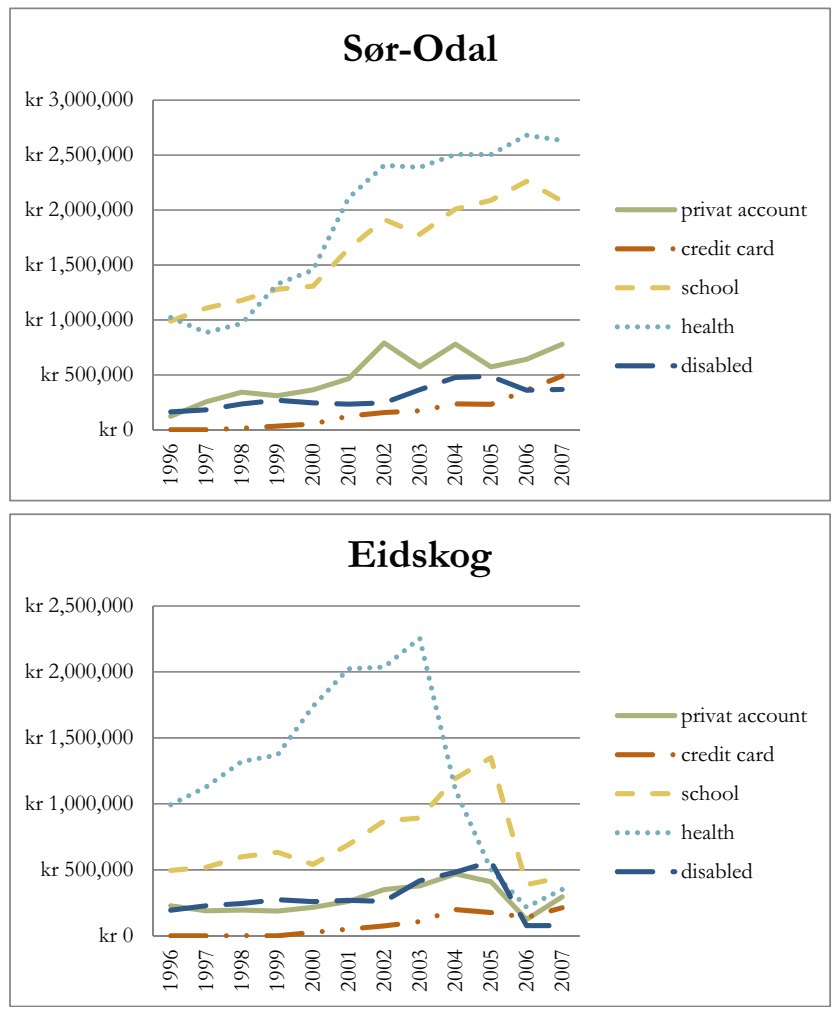

Fig. 3 a, b Turnover in different taxi market segments, with retained and lost tenders (Norwegian kroner), adopted from [1] between these and the introduction of competitive tendering. As illustrated in Fig. 4b, however, in some areas there has been a significant loss of service resulting from the taxi service industry losing tenders to the minibus industry. This has affected the supply of taxis not just in the contract market, but in adjacent market segments, too. Also, as the allocation of taxi licences is subject to a needs test, and tenders require that capacity be documented when a bid is submitted, there is a significant likelihood that the taxi service will be permanently reduced in response to the loss of tendered contracts to the minibus industry. The main factor limiting competition between taxis from different dispatchers is geographical distance and the cost associated with empty kilometres [6].

As for unit price development, it is clear that, on average, competitive tendering has resulted in lower prices. The experience from the bus industry indicates that this effect is linked to the introduction of competitive tendering, and that the future development of prices will follow the cost index [11]. There is still scope for vehicles being used more efficiently

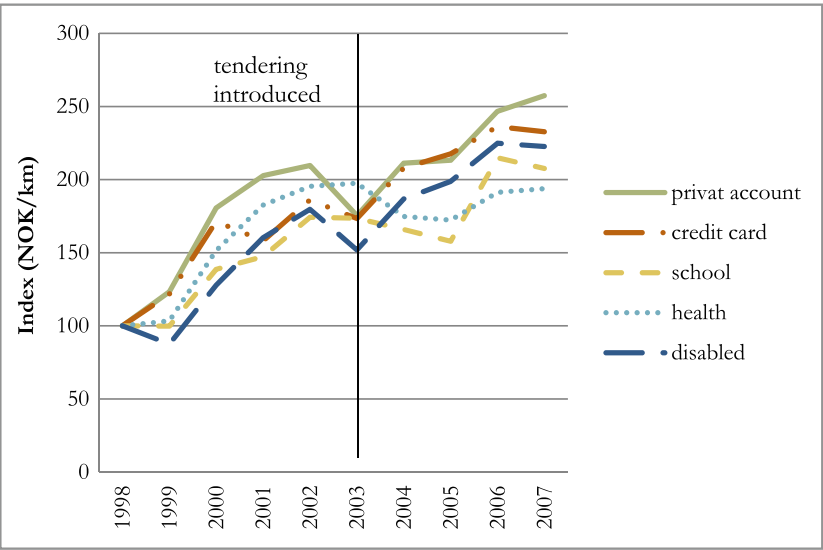

Fig. 4 Indexed price development (NOK/km) 


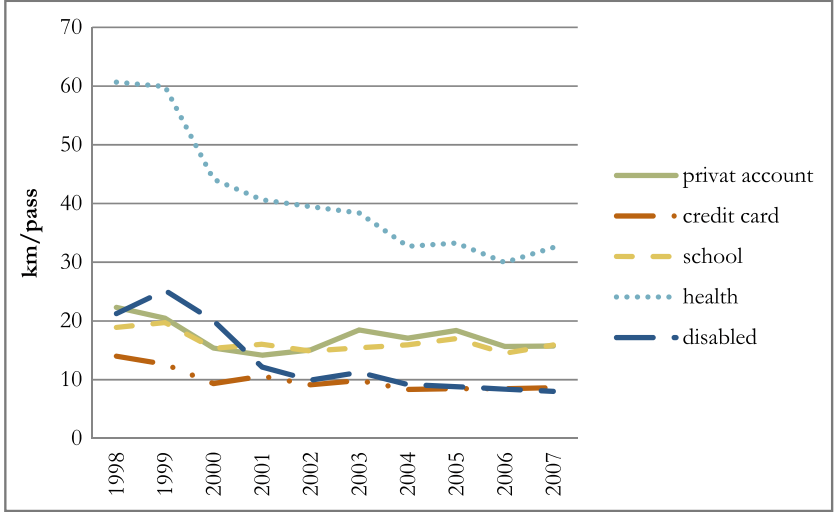

Fig. 5 Kilometres driven per passenger, Oppland county

and for technological developments contributing to further reductions in unit costs. In one interview, a taxi owner indicated that he expected a $30 \%$ reduction of his unit costs as a result of his changing from diesel to hybrid petrol-electric vehicles.

Generalising about a very specific market is difficult. However, the empirical findings in this and [1] suggest that competitive tendering works well in markets where there is a sufficient number of potential service providers-even in entry-regulated markets - and where each tendered contract constitutes a small part of the total market. In other words, there is no contradiction between entry regulation and use of competitive tendering, even in small markets such as the taxi industry in general. However, in areas where there are one or two service providers and the tendered contracts constitute a large proportion of the total market, there are challenges. In areas where there is only one potential provider, there is no competition and competitive tendering is not a suitable way of public procurement. Nevertheless, from a macro perspective, Osland et al. [1] showed that in the case of rural taxis this did not result in loss of service. The most likely explanation is the interdependence between service provider and purchaser.

\section{Conclusions}

Competitive tendering and entry regulations are difficult to combine, particularly in smaller markets. Still, in the case of Norway this has not had dramatic consequences, probably because of the lack of competition in rural communities. On average, unit prices have dropped, but there are reports of isolated cases of higher prices. In general, the quality of the service has improved, although there are examples to the contrary. This research has shown that, within the Norwegian regulatory framework, the challenge has not been to maintain services to the outermost rural areas, as was the case in Sweden, but to maintain the service in communities between these areas and regional centres. This could be attributed to the fact that in the outermost rural areas the entry regulation protects the incumbent from competition. In the in-between areas, where the markets are larger, the taxi service industry is faced with much stiffer competition from the minibus industry, which is not entry regulated, and has a different cost structure.

A lesson learned from the Norwegian experiment of combining competitive tendering with entry regulation is that it works, at least in the short and medium term. However, it is not without issue. Actors from both the minibus and taxi industries in competition over the same contracts creates more competition. Different regulation means different cost profiles, and the effects on adjacent market segments can be significant. A solution could be to link vehicle licences to the tender or to include within contracts the non-profitable services that taxi licence-holders are required to meet, so that the public will not experience loss of service if or when a non-taxi licence-holder is selected for transport on the part of the health corporations.

In summary, the experience in the Norwegian taxi service industry is that competitive tendering is no universal quick fix. In markets where the public authority has a series of policy objectives, purchase of transport services should reflect this to some extent. This can be done either by including the non-market services in the tenders or by requiring these service obligations to be met by all operators. The evidence suggests that competitive tendering is effective in creating price competition, where more than one actor can provide the service. However, the experience also shows that the heterogeneity between sectors and between markets within the same sector can result in different market responses to the same regulation. This highlights the need to look carefully at each market, and choose the method for procurement suited for that particular market.

Open Access This article is distributed under the terms of the Creative Commons Attribution 4.0 International License (http:// creativecommons.org/licenses/by/4.0/), which permits unrestricted use, distribution, and reproduction in any medium, provided you give appropriate credit to the original author(s) and the source, provide a link to the Creative Commons license, and indicate if changes were made.

\section{References}

1. Osland O, Aarhaug J, Longva F (2010) Drosjetilbudet i distriktene etter omleggingen av pasienttransporten i 2004. (Norwegian "Taxi services in rural areas"), ТØI-rapport 1086/2010. Institute of Transport Economics, Oslo

2. Longva F, Osland O, Leiren MD (2010) Omreguleringer i drosjemarkedet- hvilke alternative fines og hva blir konsekvensene, (Norwegian, Regulation of the Norwegian taxi service industryalternatives and consequences), TØI-rapport 1054/2010. Institute of Transport Economics, Oslo 
3. Aarhaug J (2014) Taxis as urban transport. TØI-report 1308/2014

4. Aarhaug J, Krogstad JR, Skollerud K (2012) Drosjer i Trondheim-konkurranse på like vilkår?, TØI-rapport $1207 / 2012$

5. Aarhaug J, Skollerud K (2011) Drosjer i Grenland-marked, løyver og sentraler, (Norwegian: taxis in the Grenland region of Norway-market, licenses and dispatchers) TØI-rapport $1144 / 2011$

6. Aarhaug J, Skollerud K, Hagman R (2013) Drosjer i Østfold—Et marknad i utvikling, (Norwegian: taxis in the Østfold region-an evolving market) TØI-rapport 1256/2013

7. McAfee RP, McMillan J (1987) Auctions and bidding. J Econ Lit 25(2):699-738

8. Bekken J-T, Longva F, Fearnley N, Osland O (2006) Norwegian experiences with tendered bus services. Eur Transp, Year XI, Number 33, August 2006

9. Arnott R (1996) Taxi travel should be subsidized. J Urban Econ 40: 316-333

10. Alexandersson G, Pyddoke R (2003) Bus deregulation in Sweden revisited: experiences from 15 years of competitive Tendering. 8th
International Conference on Competition and Ownership in Land Passenger Transport, Rio de Janeiro, Brazil

11. Aarhaug J (2009) Konkurranse og anbud i lokal rutebiltrafikk, (Norwegian, competition and tendering in local public transport) TØI- rapport 1031/2009

12. Mathisen TA, Solvoll G (2008) Competitive tendering and structural changes: an example from the bus industry. Transp Policy 15:111, www.elesevier.com

13. Frank C (2005) Microeconomics - principles and analysis. Oxford University Press

14. Frøysadal E, Bøe K (1998) Sluttrapportering av syketransportprosjektet. Særtrykk 131/1998, Transportøkonomisk institutt

15. Moore AT, Balaker T (2006) Do economists reach a conclusion on taxi deregulation? Econ J Watch 3(1):109-132

16. Pagano AM, McKnight CE (1983) Economics of scale in the taxicab industry. J Transp Econ Policy 17(3):299-313

17. Akerlof GA (1970) The market for "Lemons": quality uncertainty and the market mechanism. Q J Econ 84(3):488-500

18. Bertrand J (1883) Théorie mathématique de la richesse sociale. J Sacants, 499-508 